\title{
Nucleotype and phenotype in Vicia faba
}

\author{
S. MINELLI, P. MOSCARIELLO, M. CECCARELLI \& P. G. CIONINI* \\ Dipartimento di Biologia Cellulare e Molecolare, Sezione di Citologia e Genetica Molecolare, Università di Perugia, \\ Via A. Pascoli, I-06123 Perugia, Italy
}

\begin{abstract}
Following the results of a previous investigation which showed significant differences (up to 34.6 per cent) in the basic amount of nuclear DNA between local populations of Vicia faba, the development of plants obtained from seeds collected from different populations was studied. Both cell proliferation in the meristems and cell enlargement in differentiated tissues are affected by the genome size. DNA content and the mitotic index in the root meristem are negatively correlated. The higher proportion of cells entering mitosis in the meristems of plants with a lower amount of DNA is not the result of alterations of the duration of the mitotic cycle, which was found to be quite comparable in two populations with largely differing genome sizes. Cell growth was studied in the epicotyl cortex and the leaf epidermis. In both differentiated tissues, cells were longer or had larger surface areas in populations with higher amounts of DNA than in populations with lower amounts of DNA. By studying plant development, positive correlations were found between the genome size and both the germination power of the seeds and the growth rate of the epicotyl. In contrast, negative correlations were found between the basic amount of nuclear DNA and both the height of the main stem and the fresh weight of plants at anthesis. The possible role that intraspecific alterations of the nucleotype may play in environmental adaptation and species evolution is briefly discussed.
\end{abstract}

Keywords: cell growth, cell proliferation, intraspecific DNA changes, nucleotype, plant development, Vicia faba.

\section{Introduction}

It is now generally accepted that intraspecific changes in the basic amount of nuclear DNA do occur, as many reports to this effect can be found in the literature (reviewed, for plants, by Bennett, 1985; Cullis, 1990; Cavallini \& Natali, 1991).

Redundancy variation of DNA sequences may accompany certain developmental processes (Cionini, 1989; Bassi, 1990; Nagl, 1990) or correlate with differing environmental factors (Ceccarelli et al., 1992; Maggini et al., 1995 and references therein). Thus, these DNA changes have been suggested to play a role in development and/or in environmental adaptation. This view has recently found confirmation in the observation that intraspecific alterations of the genome size may affect certain characters of the cellular and/or organismal phenotype (Karp et al., 1982; Cavallini et al., 1993; Ceccarelli et al., 1993; Natali et al., 1993; Frediani et al., 1994).

\footnotetext{
*Correspondence.
}

Repeated DNA sequences, and particularly noncoding highly repeated sequences, are involved as a rule in intraspecific genome size alterations. This suggests that these nuclear DNA changes affect the phenotype by altering the nucleotype (i.e. the nuclear mass and volume; Bennett, 1985) rather than by producing more qualitative changes in the genotype. The significant correlations between genome size and phenotypic characters which have been found by studying a number of plants in certain species back this idea (Cavallini et al., 1993; Ceccarelli et al., 1993; Natali et al., 1993). It may also find support in the observation that certain effects on the phenotype of intraspecific genome size variations are quite similar to those produced by the presence of supernumerary chromosomes in the nucleus (Ceccarelli et al., 1993).

Changes in the basic amount of nuclear DNA do not affect the same phenotypic characters, or do not affect them in the same way, in the few plant species studied so far in this respect, probably on account of the genetic diversity occurring between them. For example, genome size correlates positively with cell 
enlargement in Helianthus annuus and Pisum sativum, whereas no such correlation can be found in Festuca arundinacea. The correlation between the amount of DNA and plant growth rate is negative in $F$. arundinacea whereas it is positive in $P$. sativum and nonexistent in $H$. annuus. The generation time is correlated positively with the genome size in $F$. arundinacea and $H$. annuus, whereas no such correlation exists in P. sativum (data in Cavallini et al., 1993; Ceccarelli et al., 1993; Natali et al., 1993). On account of the preceding, the effects of changes in the basic genome size on developmental dynamics and phenotypic characters at the cellular and organismal level seem to be worth studying in other plant species.

Significant differences in the basic amount of nuclear DNA (up to 34.6 per cent) were recently demonstrated to occur between local populations of Vicia faba collected from the Mediterranean Basin. The lengths of the chromosome complements at metaphase were found to vary in correlation with the changes in genome size, and these differences between populations were particularly apparent when comparing certain chromosome pairs. Changes in the redundancy of repeated DNA sequences, particularly of tandemly repeated FokI elements about $60 \mathrm{bp}$ in length, were proven to be involved in genome size alterations. FokI repeats were found to represent up to 9.47 per cent of the $V$. faba genome and their copy number was shown to vary in the accessions studied from $21.51 \times 10^{6}$ to $5.39 \times 10^{6}$ (Ceccarelli et al., 1995).

The developmental and phenotypic features at the cellular and organismal level of $V$. faba plants with different genome sizes seemed worth investigating in relation to the above-mentioned need to increase knowledge on the relationships between nucleotype and phenotype in plants. Besides its theoretical interest, this investigation may be of importance also on account of the agricultural interest of the species studied. Indeed, the identification of correlations between nuclear characters and phenotypic features of plants may represent a useful tool for its genetic improvement.

\section{Materials and methods}

\section{Plants}

Seeds of 30 local populations of Vicia faba (kindly provided by the Istituto del Germoplasma, CNR, Bari, Italy) with known genome size (Ceccarelli et al., 1995) were washed in tap water and allowed to germinate in damp vermiculite under sterile condi- tions at $20^{\circ} \mathrm{C}$. Some plantlets were used as experimental materials in cytological studies after the treatments listed below. Other plantlets were pricked out in Jiffy pots into compost which had been sterilized by autoclaving, and were grown in the greenhouse for 30 days. Thereafter, the plants were planted out in the open air in the experimental field and grown to their full development.

\section{Cytology}

To determine the mitotic index in the meristems, 2 $\mathrm{cm}$ long primary roots were fixed in 3:1 ethanol: acetic acid (v/v) and Feulgen-stained after hydrolysis in $\mathrm{N} \mathrm{HCl}$ at $60^{\circ} \mathrm{C}$ for $8 \mathrm{~min}$. Root tips were squashed under a coverslip which was then removed by the solid $\mathrm{CO}_{2}$ method, and the preparations were dehydrated and mounted in DPX (BDH Chemicals).

The duration of the mitotic cycle and its phases in the root meristem was calculated according to Quastler \& Sherman (1959) and Wimber (1960). Seedlings were treated for $30 \mathrm{~min}$ at $20^{\circ} \mathrm{C}$ with an aqueous solution of ${ }^{3} \mathrm{H}$-thymidine (The Radiochemical Centre; specific activity $6.7 \mathrm{Ci} \mathrm{m^{-1 }}$ ) at a concentration of $5 \mu \mathrm{Ci} \mathrm{mL} \mathrm{m}^{-1}$ and, after a thorough washing, they were recovered in water. The primary roots were collected after 2-30 h of recovery and then fixed, Feulgen-stained and squashed as described above. The preparations were then covered with Ilford $\mathrm{L}_{4}$ emulsion and developed after 7 days of exposure. The percentages of labelled mitoses after different recovery durations were scored.

With the purpose of studying cell growth, epicotyls of seedlings fixed as described above were embedded in paraffin and sectioned at $10 \mu \mathrm{m}$. With the same intention, the upper epidermis of fully developed leaves collected at the third node from the base of main stems was peeled off after fixation. Sections and peels were stained with Delafield's haematoxylin (Merck). The length of cells of the epicotyl cortex was measured on images obtained by the use of a microprojector. The surface area of cells of the leaf epidermis was determined on microphotographs by means of a planimeter.

\section{Plant development}

Seed germination was checked daily, and the germination power of equally aged seeds of different local populations was evaluated according to Davet-Fresia \& Valdeyron (1966).

The distance from the ground of the first node of plantlets growing in Jiffy pots was measured daily 
during the first 3 weeks after seed germination. The height (from the first node to the base of the apical bud) of the main stem of plants grown as described above was measured every week until they flowered. A plant was considered to be at anthesis when it had an opened flower, and a group of plants was considered to be at anthesis when 50 per cent of individuals reached this developmental stage. The following quantitative characters of individual plants were determined: (i) fresh weight at anthesis; (ii) number of branches; (iii) number of pods; (iv) number of seeds; (v) fresh weight of seeds; and (vi) weight of dry seeds. Seeds were allowed to dry at $25^{\circ} \mathrm{C}$ in the presence of silica gel until the water content was 6 per cent, as determined by comparing their weight with the fresh weight.

\section{Results}

\section{Cell proliferation and growth}

The correlation between the mitotic index in the root meristem and the basic amount of DNA of ten local populations differing in genome size (DNA C-values from $10.94 \mathrm{pg}$ to $14.29 \mathrm{pg}$ ) is shown in Fig. 1. It can be seen that this correlation is significant and negative $(r=-0.732 ; P=0.016)$; the lower the genome size of a population, the higher the proportion of meristematic cells entering mitosis. The different numbers of cells caught at karyokinesis in the meristems of different populations did not depend on alterations of the length of time of the

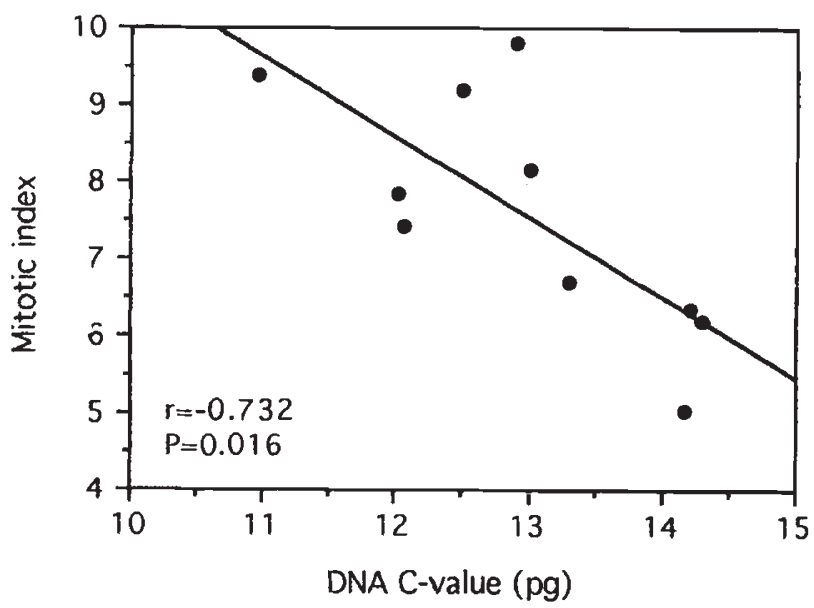

Fig. 1 Correlation between the mitotic index in the meristem of the seminal root and the genome size in ten local populations of Vicia faba. Two thousand cells in each of five seedlings per population were studied. For this correlation and those given in Figs 4-7, DNA C-values were taken from Ceccarelli et al. (1995). mitotic cycle. The duration of the mitotic cycle and its phases was calculated in two local populations largely differing in genome size (11.28 pg vs. 14.29 $\mathrm{pg}$ ). The results obtained show that the times of the mitotic cycle are quite comparable in the two populations (Fig. 2).

The data given in Fig. 3 and Table 1 indicate that

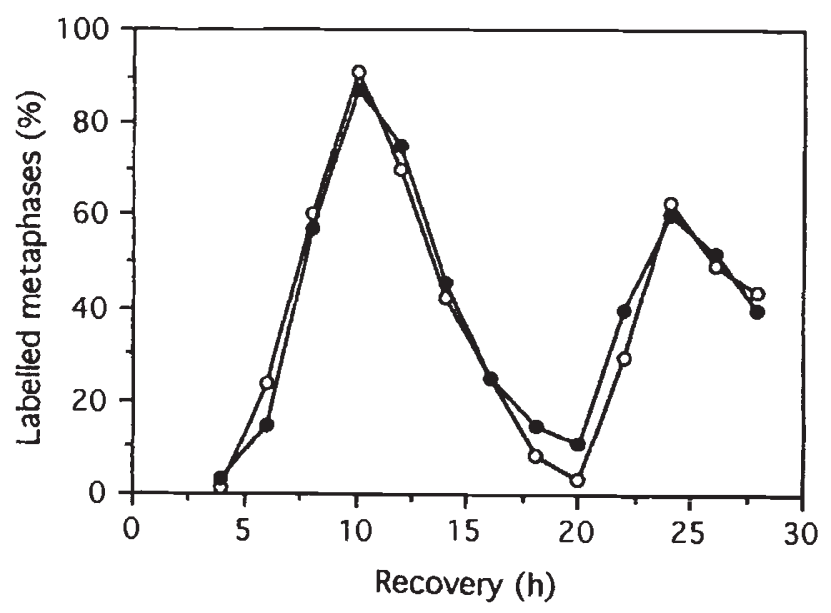

Fig. 2 Percentage of metaphases labelled after a feeding with ${ }^{3} \mathrm{H}$-thymidine lasting $30 \mathrm{~min}$, followed by different recovery times in water. Each point is the mean of the values obtained by analysing the root meristems of five seedlings obtained from seeds of two local populations of Vicia faba differing in genome size: accession 106367 from Algeria (O) and accession 106858 from Greece (•). Their DNA C-values are $14.29 \mathrm{pg}$ and $11.28 \mathrm{pg}$, respectively (Ceccarelli et al., 1995).

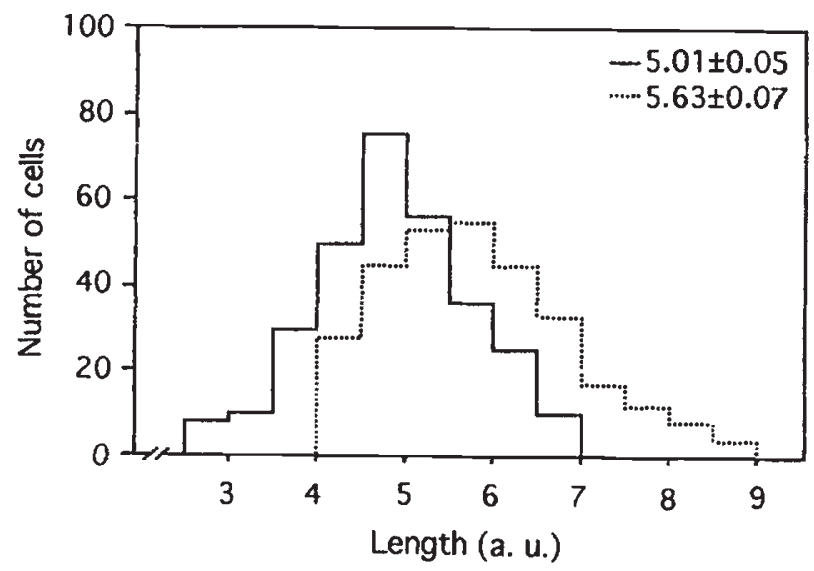

Fig. 3 Length of parenchymatic cells in the epicotyl cortex of Vicia faba seedlings obtained from seeds of accession 113071 from Italy ( - ) and 106367 from Algeria $(\cdots \cdots)$. The mean length $( \pm S E)$ in each accession is indicated. The 1C DNA value of accession 113071 is 13.01 pg; that of accession 106367 is 14.29 pg (Ceccarelli et al., 1995).

(c) The Genetical Society of Great Britain, Heredity, 76, 524-530. 
Table 1 Surface area of epidermal cells in the leaf lamina of plants obtained from seeds of local populations of Vicia faba differing in genome size

\begin{tabular}{llccc}
\hline & & & \multicolumn{2}{c}{ Portion of the leaf lamina } \\
\cline { 4 - 5 } Accession & Country & $\begin{array}{c}\text { 1C DNA value } \\
(\mathrm{pg}) *\end{array}$ & Basal & Apical \\
\hline 107214 & Spain & 12.90 & $70.03 \pm 1.58$ & $56.40 \pm 1.04$ \\
113071 & Italy & 13.01 & $68.35 \pm 2.09$ & $53.33 \pm 1.05$ \\
111895 & Lybia & 14.16 & $82.20 \pm 2.10$ & $68.89 \pm 1.59$ \\
106367 & Algeria & 14.29 & $80.98 \pm 2.11$ & $65.81 \pm 1.05$ \\
\hline
\end{tabular}

Values are $\mu \mathrm{m} \pm \mathrm{SE}$.

Fifty cells were measured in each portion of three leaves for each accession.

* Data from Ceccarelli et al. (1995).

differences in the basic amount of nuclear DNA between local populations of $V$. faba may affect cell growth with tissue differentiation. Indeed, a $t$-test $(P<0.001)$ showed parenchymatic cells in the epicotyl cortex to be significantly longer in a population with a DNA C-value of $14.29 \mathrm{pg}$ than in a population with a DNA C-value of 13.01 pg (Fig. 3). Cell growth was also studied by measuring the surface area of cells of the leaf epidermis in four local populations two of which have relatively low DNA C-values (12.90 pg and $13.01 \mathrm{pg}$, respectively) and two of which have relatively high DNA C-values (14.16 pg and $14.29 \mathrm{pg}$, respectively; Table 1). A $t$-test showed that in both the populations with higher DNA contents the cell surface areas were significantly $(P<0.001)$ larger than in the two populations with lower genome sizes. By contrast, no significant difference in cell largeness occurs within the two pairs of populations.

\section{Plant development}

Intraspecific alterations of the genome size can also affect the developmental dynamics and other phenotypic characters of plants. The correlation between the germination power of the seeds and the genome size in 20 local populations is shown in Fig. 4. This correlation is highly significant and positive $(r=0.651 P=0.0018)$. The existence of a positive correlation between genome size and early plant development is also proven by the results given in Fig. 5. The larger the basic amount of DNA of a population, the higher the growth rate of the epicotyl $(r=0.804 ; P=0.005)$.

In contrast with what has been observed by studying early plant development, certain characters of mature plants are correlated negatively with the genome size. Indeed a significant, negative correla-

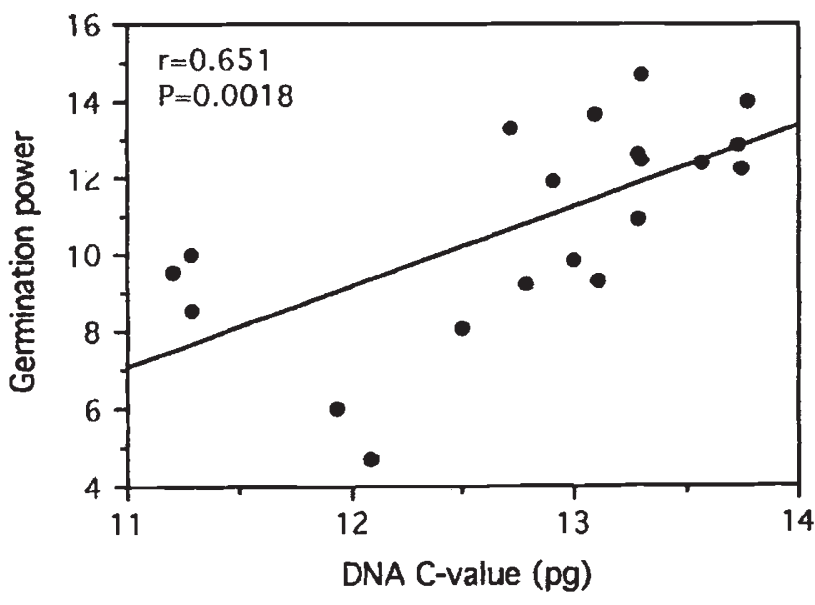

Fig. 4 Correlation between the germination power of the seeds and the genome size in 20 local populations of Vicia faba. Sixty seeds per population were germinated.

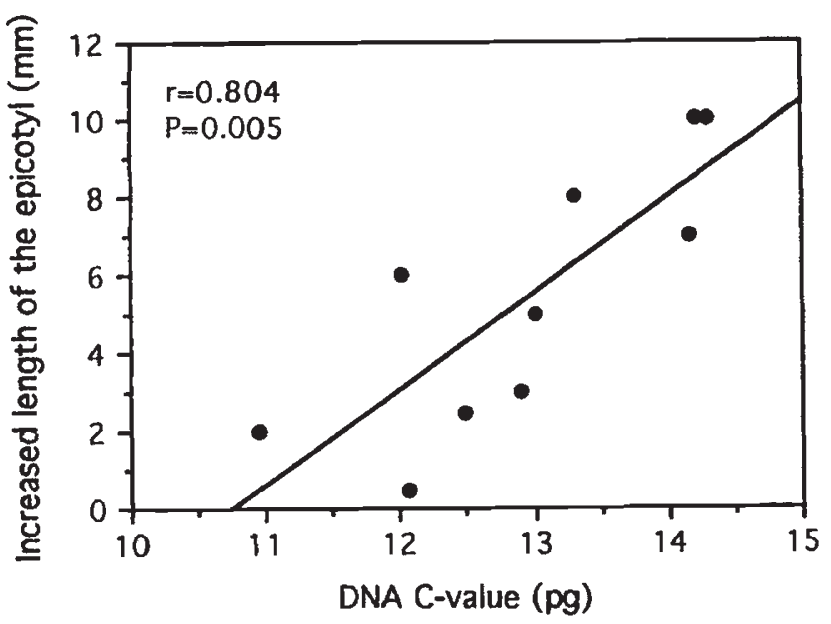

Fig. 5 Correlation between the growth rate of the epicotyl and the genome size in ten local populations of Vicia faba. The growth rate of the epicotyl was determined by comparing its length 2 and 3 days after seed germination. Twenty seedlings per population were studied. 


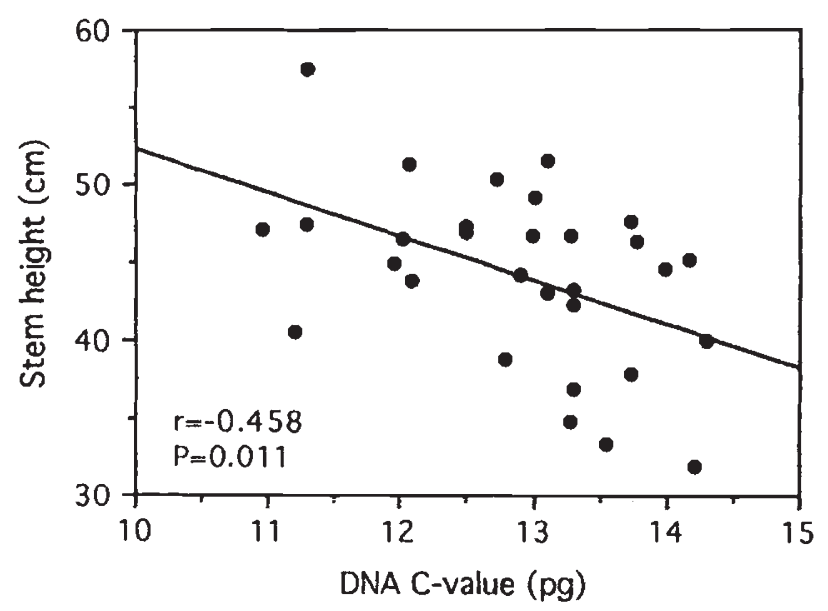

Fig. 6 Correlation between the mean height of the main stem of plants at anthesis and the genome size in 30 local populations of Vicia faba. Measurements were carried out on 20 plants per population.

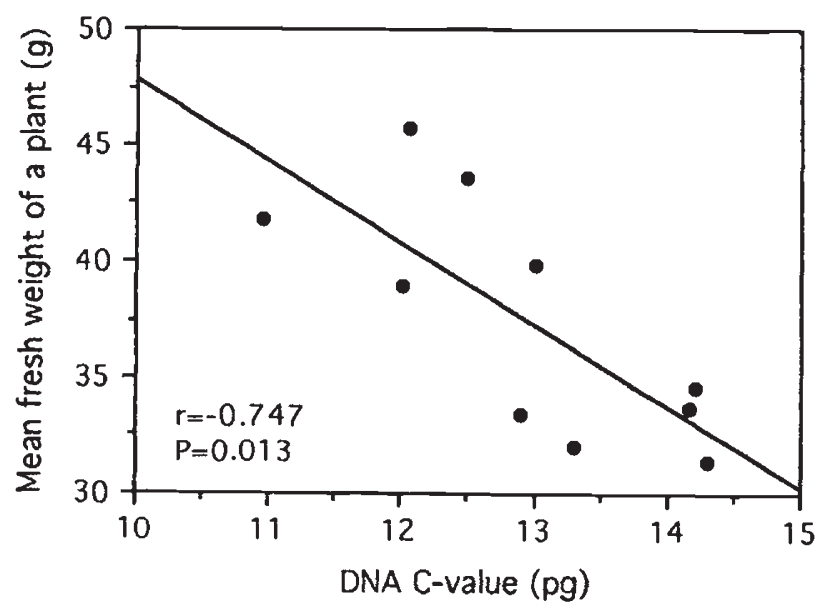

Fig. 7 Correlation between the fresh weight of plants at anthesis and the genome size in ten local populations of Vicia faba. Twenty plants per population were weighed.

tion $(r=-0.458 ; P=0.011)$ exists, in thirty local populations, between the DNA C-value and the mean height of the main stem of plants at anthesis (Fig. 6). A similar correlation between the fresh weight of mature plants and their genome size is shown in Fig. $7(r=-0.747 ; P=0.013)$. No significant correlations were found between the genome size and the other plant characters studied (see Materials and methods).

\section{Discussion}

Our observations indicate that alterations of the genome size within $V$ faba, mainly from changes in the redundancy of repeated DNA sequences in fluid genomic domains (Ceccarelli et al., 1995), correlate negatively with cell proliferation in the meristems (Fig. 1) and positively with cell enlargement in differentiated tissues (Fig. 3 and Table 1). Possibly because of this combination of events, plants with larger genomes grow faster at early developmental stages (Figs 4 and 5) but reach smaller final sizes (Figs 6 and 7) than plants with smaller genomes, and vice versa.

Genetic diversity other than that produced by alterations of the nucleotype might be claimed as determining changes in characters that were compared in a few local populations, as is the case with the cell growth in differentiated tissues (Fig. 3 and Table 1). However, we stress the data given in Table 1: cell largeness differs significantly between populations with different genome sizes and does not differ between populations in which the genome sizes are similar. Moreover, the existence of significant correlations between DNA content and plant characters found by studying a number of populations (Figs 1 and 4-7) clearly excludes genetic diversity between them of another kind as responsible for the observed changes in development. Differences of 5-10 per cent in the basic DNA amount may be sufficient to determine changes in the nucleotype expression (Price, 1988), and the genome size may differ up to 34.6 per cent between local populations of $V$. faba (Ceccarelli et al., 1995).

It may be rather surprising that changes in the basic amount of nuclear DNA affect cell proliferation in the meristems of $V$ f faba by a way other than altering the cell cycle time. Comparative studies have shown species with larger genomes to have a longer $\mathrm{S}$ phase and slower cell division cycles (Bennett, 1987). This correlation has been proven also when studying the effects on the cell phenotype of changes in the genome size within Festuca arundinacea (Ceccarelli et al., 1993) and Helianthus annuus (Natali et al., 1993). In an attempt to explain the higher proportion of cells entering mitosis in the meristems of $V$. faba plants with decreased amounts of nuclear DNA, we suggest that these genomic changes might produce alterations in the synthesis of certain substances which affect the complex hormonal gradient that exists in apical meristems and controls mitotic activity (Clowes, 1975). If this hypothesis is accepted, changes of the genome size within $V$. faba must involve redundancy variations of given genes and/or control sequences, and yield certain effects that seem to be beyond those which may more properly be considered as nucleotypic. 
Apart from this, our results, together with a few others in the literature (see Introduction), indicate that intraspecific alterations of the basic amount of nuclear DNA play a central role in inducing changes in the modalities and the rate of growth by influencing cell proliferation and/or enlargement. A similar influence of the nucleotype on development has been suggested also at the interspecific level (Moore, 1985; Bennett, 1987, and references therein). Besides in $V . f a b a$, an influence of intraspecific changes in the nucleotype on the growth of plants has also been proven in Pisum sativum (Cavallini et al., 1993) and Festuca arundinacea (Ceccarelli et al., 1993), although cell parameters are not affected in the same way in all instances (cell enlargement but not mitotic activity is affected in $\ddot{P}$. sativum, and the mitotic cycle time but not cell growth is affected in $F$. arundinacea). The effect of these genomic changes on other plant features, such as, for example, their final size, not only may be a consequence of the differences induced in the growth modalities, but may even be misinterpreted when plants of different populations are grown together in the same environment. For example, differences in the growth rate between populations might not produce differences in the final size of the plants if differing environments allow them different times to grow.

Intraspecific changes of the genome size have now been shown to occur in a number of plant species. In many cases these changes may be correlated with environmental parameters (see Introduction). As is discussed above, nucleotypic alterations within species can modulate given properties of the whole organism by affecting certain cellular behaviours. On the basis of these considerations, we suggest that intraspecific changes of the basic amount of nuclear DNA represent an evolutionary factor of widespread occurrence, which play a part in allowing species adaptive responses. Therefore, these genomic changes might have a role which has already been hypothesized for the large variations of the genome size between plant species (Bennett, 1987; Smyth, 1991). Nucleotypic changes within species may also help in explaining the extraordinary intraspecific plasticity at both the physiological and morphological level which is a common feature of plants.

\section{Acknowledgements}

Thanks are due to the staff of the Botanical Garden of the University, Perugia, for their help in growing plants in the experimental field. Research was supported by National Research Council, Italy, Special Project RAISA, Sub-project no. 2.

\section{References}

BASSI, P. 1990. Quantitative variations of nuclear DNA during plant development: a critical analysis. Biol. Rev., 65, 185-225.

BENNETT, M. D. 1985. Intraspecifc variation in DNA amount and the nucleotype dimension in plant genetics. In: Freeling, M. (ed.) Plant Genetics, pp. 283-302. A. R. Liss, New York.

BENNETT, M. D. 1987. Variation in genomic form in plants and its ecological implications. New Phytol., 106, $177-200$.

CaVAlLINI, A. AND Natali, L. 1991. Intraspecific variation of nuclear DNA content in plant species. Caryologia, 44, 93-100.

CAVALlini, A., NATALI, L., CIONINI, G. AND GENNAI, D. 1993. Nuclear DNA variability within Pisum sativum (Leguminosae): nucleotypic effects on plant growth. Heredity, 70, 561-563.

CECCARELli, M., FALISTOCCO, E. AND CIONINI, P. G. 1992. Variation of genome size and organization within hexaploid Festuca arundinacea. Theor. Appl. Genet., 83, 273-278.

CECCARELLI, M., MiNELli, S., FALCINELli, M. AND CIONINI, P. G. 1993. Genome size and plant development in hexaploid Festuca arundinacea. Heredity, 71, 555-560.

CECCARELLI, M., MINELli, S., MAGGINI, F. AND CIONINI, P. G. 1995. Genome size variation in Vicia faba. Heredity, 74, 180-187.

CIONINI, P. G. 1989. Nuclear DNA changes during plant development. Giorn. Bot. Ital., 123, 111-121.

CLOWES, F. A. L. 1975. Control of cell cycles in plant meristems. In: Ram, H. Y. M., Shah, J. J., Shah, C. K. (eds) Form, Structure and Function in Plants, pp. 34-42. Sarita Prakashan, Meerut.

CULLIS, C. A. 1990. DNA rearrangements in response to environmental stress. Adv. Genet., 28, 73-97

DAVET-FRESIA, M. AND VALDEYRON, G. 1966. L'umidité des glands de Quercus ilex L: facteur essential de leur conservation. Naturalia Monspell., Sér. Bot., 17, 97-101.

FREDIANI, M., COLONNA, N., CREMONINI, R., DE PACE, C., DELRE, V., CACCIA, R. AND CIONINI, P. G. 1994. Redundancy modulation of nuclear DNA sequences in Dasypyrum villosum. Theor. Appl. Genet., 88, 167-174.

KARP, A., REES, H. AND JEWELL, A. W. 1982. The effects of nucleotype and genotype upon pollen grain development in Hyacinthus and Scilla. Heredity, 48, 251-261.

MAGGinI, F., D'OVIDIO, R., GElati, M. T., FREDIANI, M., CREMONINI, R., CECCARELLI, M., MINELLI, S. AND CIONINI, P. G. 1995. The FokI DNA repeats in the genome of Vicia faba: species-specificity, structure, redundancy modulation, nuclear organization. Genome (in press).

MOORE, P. D. 1985. Nuclear DNA content as a guide to plant growth rate. Nature, 318, 412-413.

NAGL, W. 1990. Gene amplification and related events. In: 
Bajaj, Y. P. S. (ed.) Biotechnology in Agriculture and Forestry, vol. 11, pp. 153-201. Springer, Berlin, Heidelberg, New York.

natali, l., Cavallini, A., Cionini, G., Sassoli, o., Cioninl, P. G. AND DURANTE, M. 1993. Nuclear DNA changes within Helianthus annuus L.: chariges within single progenies and their relationships with plant development. Theor. Appl. Genet., 85, 506-512.

PRICE, H. J. 1988. DNA content variations among higher plants. Ann. Mo. Bot. Gard., 75, 1248-1257.

SMYTH, D. R. 1991. Dispersed repeats in plant genomes. Chromosoma, 100, 355-359.

QUastler, H. AND Sherman, F. G. 1959. Cell population kinetics in the intestinal epithelium of the mouse. Exp. Cell Res., 17, 420-438.

WIMBER, D. E. 1960. Duration of the nuclear cycle in Tradescantia paludosa root tips as measured with ${ }^{3} \mathrm{H}$-thymidine. Am. J. Bot., 47, 828-834. 